\title{
Listeria Meningitis After Infliximab in Ulcerative Colitis: Does the Risk of Treatment Outweigh the Benefit
}

\author{
Iyad A Issa ${ }^{1^{*}}$ and Ali Eid ${ }^{1}$ \\ ${ }^{1}$ Division of Gastroenterology, Rafik Hariri University Hospital, Beirut, Lebanon.
}

Authors' contributions

This work was carried out in collaboration between all authors. Author AE wrote the first draft of the manuscript. Author IAI adjusted and wrote the final manuscript and edited the English language. Both authors read and approved the final manuscript.

\section{Case Study}

Received $2^{\text {nd }}$ May 2013

Accepted $7^{\text {th }}$ June 2013

Published 28 ${ }^{\text {th }}$ June 2013

\section{ABSTRACT}

Biologic agents have become important treatment options for the management of inflammatory bowel disease (IBD). With more than 10 years of experience behind us these agents have changed the natural history of the disease and have established themselves as a valid choice in the repertoire used in treating not only advanced patients but also newly diagnosed ones. We report two cases of ulcerative colitis who developed listeria meningitis after a single dose of infliximab therapy. We also examined the significance of the infection and the known details and morbidity about it. We assessed the close link between the use of biologics and the risk of serious infections in patients with IBD, as well as the published cases in the literature so far. Therefore, despite the excitement and hype surrounding their use we should not forget that these are agents that carry a substantial toll of side effects and this should be kept in mind when the choice of therapy is made.

Keywords: Listeria monocytogenes; meningitis; ulcerative colitis; infliximab; biologic agents. 


\section{INTRODUCTION}

Inflammatory bowel diseases (IBD) are chronic illnesses affecting the intestinal tract. Their exact pathogenesis is unknown. The most acceptable hypothesis states that genetically predisposed subjects lose tolerance to the intestinal microbiota and as a consequence their innate and adaptive immune system unleashes an uncontrolled inflammatory reaction characterized by an excessive production of pro-inflammatory cytokines [1-3]. Tumor necrosis factor- $\alpha$ (TNF- $\alpha$ ) is one of those molecules, it plays a central role in mucosal inflammation and is a key mediator in the inflammatory cascade in both Crohn's disease (CD) and ulcerative colitis (UC) $[4,5]$. Introduction of biological therapy with anti-TNF agents created great expectation to further solve the clinical shortcomings of conventional therapy. Infliximab, is a chimeric monoclonal IgG1 anti-TNF antibody, it binds with high affinity and specificity to human TNF alpha, thereby neutralizing its biologic activity. It was the first biological therapy to be introduced in the treatment of patients with inflammatory bowel disease more than a decade ago [6]. Since then it has dramatically affected the way we approach severe IBD.

Biologic agents are associated with multiple side effects some of which are serious like infusion reactions, serum sickness-like disease, lupus-like syndrome, and severe infections [7-11]. However, the extent to which biologic agents, alone or in combination with immunosuppressive medications, increase the risk of serious infections in patients with IBD remains controversial, this is mostly due to the low number of infection rates. Large cohort studies are needed to determine their precise incidence and establish the excess risk associated with the use of a specific medication, particularly while administering older traditional therapies which have been less scrutinized, although they carry their own risks [12]. Granulomatous infections such as tuberculosis have received the greatest attention, while additional case reports suggest increased rates of infections by other pathogens (viruses, intracellular bacteria, fungi, and parasites), which have been reported to be a cause of death in this population of patients $[11,13]$.

We present hereafter two cases of Listeria monocytogenes meningitis and bacteremia after a single dose of infliximab in the treatment of ulcerative colitis. We will take this chance to review the available data about the safety profile of these agents and assess the delicate balance of risk versus benefit ratio in the context of treatment for UC.

\section{CASE 1}

A 59 year old white male was brought to the emergency department due to a progressive decrease in the level of consciousness noticed for the past 24 hours. Associated symptoms were abdominal pain, nausea, diarrhea and urine retention. There was no history of travel, or recent exposure to sick contacts. He had received his first dose of infliximab 10 days earlier for ulcerative colitis unresponsive to conventional treatment. His past medical history included dyslipidemia, coronary artery disease, and benign prostatic hypertrophy, and he was maintained on omeprazole and alfuzosin. Azathioprine had been stopped two weeks prior to presentation but he was still maintained on $30 \mathrm{mg}$ of prednisone per day.

On Physical examination, the patient was febrile $(38.5 \mathrm{c})$ with mild tachycardia. Abdominal examination revealed diffuse tenderness with hyperactive bowel sound, and no rebound tenderness. Neurological examination showed lethargy, confusion, and disorientation with no focal motor weakness, but evidence of nuchal rigidity. Initial laboratory tests showed mild 
normocytic anemia without leukocytosis. Serum chemistry was normal except for hyperphosphatemia and hyponatremia. Chest X-ray and computed tomography of the brain revealed no abnormality. A Lumbar puncture was performed showing cloudy spinal fluid, a white cell blood count of $350 / \mathrm{mm} 3(71 \%$ segmented), a total protein of $92 \mathrm{mg} / \mathrm{dl}$ and glucose of $22 \mathrm{mg} / \mathrm{dl}$. These findings were consistent with bacterial meningitis; therefore blood cultures were drawn and the patient was admitted to the intensive care unit. Empirical treatment with ceftriaxone and vancomycin was started. The gram stain of the cerebrospinal fluid was normal but the final culture revealed Listeria monocytogenes. The patient was shifted to ampicillin $2 \mathrm{~g}$ intravenously every 6 hour in accordance with the sensitivity, but despite appropriate antimicrobial therapy, his condition continued on deteriorating with persistent high grade fever and deeper lethargy. On the $3^{\text {rd }}$ day of admission he sustained a cardio-pulmonary arrest from which he never recovered adequately. He passed away 2 weeks later secondary to multi-organ failure.

\section{CASE 2}

A 39 year old white male presented to our emergency department due to a progressive decrease in the level of consciousness for the past 48 hour. Associated symptoms included headache, nausea and vomiting. There was no history of travel, or recent exposure to sick contacts and the past medical history was negative. He had received his first dose of infliximab about one week earlier for ulcerative colitis after failure of standard therapy. His medications included prednisone $(40 \mathrm{mg})$ and azathioprine. On Physical examination, the patient was febrile (38c) and tachycardic (100/min). Abdominal examination was unremarkable. Neurological examination revealed a somnolent patient although responsive to verbal commands, confused, disoriented with evidence of nuchal rigidity. Initial laboratory tests showed normal CBC and elevated creatinine level with hyponatremia. Chest X-ray and computed tomography of the brain were normal. A Lumbar puncture was performed revealing cloudy spinal fluid, white cell blood count of $680 / \mathrm{mm} 3$ with $100 \%$ lymphocyte count, total protein of $55 \mathrm{mg} / \mathrm{dl}$, and a glucose of $21 \mathrm{mg} / \mathrm{dl}$. Again findings were suggestive of meningitis; blood cultures were taken, magnetic resonance imaging (MRI) of the brain to rule out encephalitis was done and the patient was admitted to the intensive care unit. Empirical treatment with ceftriaxone, vancomycin, and ampicillin was started as well as anti tuberculous and antiviral medications. The culture grew beta haemolytic colonies after 48 hours and Listeria monocytogenes was confirmed later.

The patient was kept on ampicillin, and all other medications were discontinued. By day 7 his mental status returned to baseline, treatment was continued for a full course of 21 days. He was later discharged home after complete recovery. He is still followed up in our out-patient department but infliximab was never reintroduced.

\section{DISCUSSION}

The incidence of inflammatory bowel disease varies widely according to the geographical area and has been reported to have increased in the last few years, roughly by almost 3 folds for CD and 2 folds for UC [14-16].

Recently, the progressive description of the cell signaling cascade has led to a surge in new potential treatment options. Development of these tumor necrosis factor blockers dramatically changed the course of IBD. Infliximab, Adalimumab and Certolizumab pegol are currently FDA approved for the treatment of moderate to severe luminal and fistulizing 
crohn's disease [17-24]. Their use in CD is well established and they are currently part of the standards of care in almost all institutions. In addition newer data is advocating earlier use of combination therapy with infliximab and (azathioprine) AZA in naïve patients and suggesting a better long term outcome [25].

Despite the presence of notable side effects the justification for the use of anti-TNFs in CD seems simpler and the arguments look clear. However, in UC things get complicated, it is only a mucosal disease that is characterized by a more variable disease course. A recent analysis of the prospective Norwegian cohort has shown that after an initial disease flare, $55 \%$ of patients are well controlled with amino-salicylates or no therapy for at least a 5-year period [26]. In general about one quarter of patients develops fulminating disease and $20 \%$ require surgery [27].

Infliximab was licensed for moderate to severe UC after two large randomized controlled trials ACT 1 and ACT 2, it has been clearly shown to be effective in inducing and maintaining remission in difficult to manage patients [28]. In addition it has become an alternative to cyclosporine as rescue therapy in acute severe UC failing first-line medical therapy $[29,30]$. To date, two large series assessing the long-term safety profile of IFX in clinical practice were published [31,32], and two additional cohorts of IBD patients are still on-going for the same purposes recently $[33,34]$. Current clinical experience has confined the initial fears of this drug's safety profile into three main groups of adverse effects: infections, immunerelated conditions and carcinogenesis. It seems that when IFX is used alone the safety profile is quite acceptable compared to other modes of more conventional therapy. This large Belgian study on the IFX safety profile found that the risk of severe infections was significantly increased among IFX-treated patients when concomitant steroids were administered [35]. The benefits and risks of combination therapy are a primary focus in terms of both efficacy and side effects. In this context, a case-control study by Toruner et al. [36] is of fundamental importance. They recently demonstrated that combinations of immunosuppressant therapies in IBD patients are associated with an incremental increase in the relative risk of opportunistic infections (OI). Specifically, patients experienced a three-fold increased risk for Ols if corticosteroids, AZA / 6- MP or IFX were used alone, and the risk increased substantially if two or more drugs were used concomitantly [36].

Listeria Monocytogenes is an aerobic gram positive intracellular bacillus that predominantly affects women, immune-compromised patients and elderlies. It can be acquired through food, notably uncooked meat, soft and unpasteurized cheese or unwashed vegetables. Recently in the USA an outbreak of food listeriosis showed to be one of the deadliest foodborne outbreaks in the US history [37]. Although 1-5\% of healthy adults are asymptomatic carriers of L. monocytogenes, approximately 2500 cases of listeriosis are reported yearly with a significant mortality reaching $30 \%$. It is the highest of all food-borne pathogens tracked by the Center for Disease Control and Prevention [38]. It is very difficult to estimate the incidence of Listeria in this specific population, but in 2006 Dixon et al. reported three cases of listeriosis in 7664 patients treated with anti-TNF [39]. This suggests a rough incidence of 3 in 10,000 patient-years and this is much higher than the rate for the general population. It has been shown that administration of TNF to mice can enhance resistance to experimental listerial infection [40]. Furthermore, injection of antibodies against TNF results in increased growth of listeria and overwhelming infection [41,42]. The first infection caused by $L$ monocytogenes complicating infliximab treatment of inflammatory bowel disease was reported in 2000 in a patient with CD [43]. In 1999 a review of the Food and Drug Administration (FDA) showed 15 cases of Listeria infection in patients treated with anti-TNF therapy resulting in 6 deaths [38]. A recently published review revealed a total of 43 cases 
reported until now of invasive Listeria infection associated with anti-TNF [44]. Of these 38 $(88 \%)$ were related to infliximab, 14 cases (33\%) had a diagnosis of CD but only 1 patient had UC (2\%). $95 \%$ of cases were maintained on at least one additional immune-suppressive agent. Listeria infection was neurological in $58 \%$ of patients. Most of whom developed the infection soon after the start of therapy with two thirds of patients having three or less infusions given. Fifteen death were reported in total but none since 2005. To our knowledge, so far only 3 cases of Listeria in UC patients on IFX treatment are reported.

However, unlike CD, in UC we can ultimately resort to colectomy [45]. The most common surgical procedure performed is total procto-colectomy with ileal pouch-anal anastomosis (IPAA), which can result in an acceptable complication rate profile, good functional outcome, and an improved quality of life [46-48]. Nonetheless, it is not adverse events free, several side effects can be encountered: small bowel obstruction in $2 \%$ to $13 \%$ [49-52], anastomotic stricture in $9 \%$ to $24 \%$ [53-55], pouch leakage in $5 \%$ to $18 \%$ [56-58] and most commonly pouchitis in $8 \%$ to $48 \%$ [59-60]. Whether infliximab can prevent this outcome, particularly in those with severe and refractory disease, is still under question. Such patients may be exposed to the risk and expense of infliximab treatment while not preventing (or only delaying) subsequent colectomy. New data have shown that in patients who received infliximab treatment for refractory U.C the probability of maintaining colectomy free survival was $83.5 \%, 77.8 \%, 75.7 \%$, and $61.4 \%$ at $1,2,3$, and 6 years, respectively [61], while longer outcome is still not clear. On the other hand patients treated with infliximab prior to surgery have substantially increased postoperative pouch-related and infectious complications [62].

\section{CONCLUSION}

We presented two cases of Listeria monocytogenes meningitis after a single dose of infliximab in the treatment of ulcerative colitis, both of them were on combined immunosuppressive medication. One of them ended up with a fatal outcome. This serves to remind us that the treatments we currently use are not devoid of serious side effects. It would be a good policy to always balance benefits versus risks in IBD patients especially if one is dealing with ulcerative colitis. This obviously contradicts the recent thinking advocated by the top-down therapy approach, at least in the particular setting of ulcerative colitis.

Physicians treating patients with anti-TNF therapy should be aware of the possibility of the development of serious infections; especially listeriosis, particularly in the context of concomitant immunosuppressive medication in these severely ill patients.

\section{CONSENT}

Authors may use the following wordings for this section: "All authors declare that 'written informed consent was obtained from the patient (or other approved parties) for publication of this case report and accompanying images.

\section{ETHICAL APPROVAL}

Not applicable. 


\section{COMPETING INTERESTS}

The authors report no conflict of interest.

\section{FUNDING}

Authors have received no funding for this manuscript.

\section{REFERENCES}

1. Fiocchi C. Inflammatory bowel disease: etiology and pathogenesis. Gastroenterology. 1998;115:182-205.

2. Danese S, Fiocchi C. Etiopathogenesis of inflammatory bowel diseases. World J Gastroenterol. 2006;12:4807-12.

3. Baumgart DC, Sandborn WJ. Inflammatory bowel disease: clinical aspects and established and evolving therapies. Rev. Lancet. 2007;12:1641-1657.

4. Armstrong AM, Gardiner KR, Kirk SJ, Halliday MI, Rowlands BJ. Tumour necrosis factor and inflammatory bowel disease. Br J Surg. 1997;84:1051-58.

5. Van Deventer SJ. Review article: targeting TNF alpha as a key cytokine in the inflammatory processes of Crohn's disease - the mechanisms of action of infliximab. Aliment Pharmacol Ther. 1999;13(Suppl 4):3-8.

6. Hanauer SB, Feagan BG, Lichtenstein GR, et al. Maintenance infliximab for Crohn's disease: the ACCENT I randomised trial. Lancet. 2002;359(9317):1541-9.

7. Colombel J, Loftus EV, Tremaine WJ, et al. The safety profile of infliximab in patients with Crohn's disease: the Mayo clinic experience in 500 patients. Gastroenterology. 2004;126(1):19-31.

8. Lees CW, Ali Al, Thompson Al, et al. The safety profile of anti-tumour necrosis factor therapy in inflammatory bowel disease in clinical practice: analysis of 620 patientyears follow-up. Aliment Pharmacol Ther. 2009;29(3):286-97.

9. Lichtenstein GR, Feagan BG, Cohen RD, et al. Serious infections and mortality in association with therapies for Crohn's disease: TREAT registry. Clin Gastroenterol Hepatol. 2006;4(5):621-30.

10. Toruner M, Loftus EV, Harmsen WS, et al. Risk factors for opportunistic infections in patients with inflammatory bowel disease. Gastroenterology. 2008;134(4):929-36.

11. Ljung T, Karle'n P, Schmidt D, et al. Infliximab in inflammatory bowel disease: clinical outcome in a population based cohort from Stockholm County. Gut. 2004;53(6):84953.

12. Viget N, Vernier-Massouille G, Salmon-Ceron D, et al. Opportunistic infections in patients with inflammatory bowel disease: prevention and diagnosis. Gut. 2008;57(4):549-58.

13. Gea-Banacloche JC, Weinberg GA. Monoclonal antibody therapeutics and risk for infection. Pediatr Infect Dis J. 2007;26(11):1049-52.

14. Loftus EV Jr, Sandborn WJ. Epidemiology of inflammatory bowel disease. Gastroenterol Clin North Am. 2002;31:1-20.

15. Shivananda S, Lennard-Jones J, Logan R, Fear N, Price A, Carpenter L, et al. Incidence of inflammatory bowel disease across Europe: is there a difference between north and south. Results of the European Collaborative Study on Inflammatory Bowel Disease (EC-IBD). Gut. 1996;39: 690-7. 
16. Kappelman MD, Rifas-Shiman SL, Kleinman K, Ollendorf D, Bousvaros A, Grand RJ, et al. The prevalence and geographic distribution of Crohn's disease and ulcerative colitis in the United States. Clin Gastroenterol Hepatol. 2007;5:1424-9.

17. Colombel JF, Sandborn WJ, Rutgeerts $P$, et al. Adalimumab for maintenance of clinical response and remission in patients with Crohn's disease: the CHARM trial. Gastroenterology. 2007;132:52-65.

18. Hanauer SB, Feagan BG, Lichtenstein GR, et al. Maintenance infliximab for Crohn's disease: the ACCENT I randomised trial. Lancet. 2002;359:1541-9.

19. Hanauer SB, Sandborn WJ, Rutgeerts $P$, et al. Human anti-tumor necrosis factor monoclonal antibody (adalimumab) in Crohn's disease: the CLASSIC-I trial. Gastroenterology. 2006;130:323-33.

20. Sandborn WJ, Hanauer SB, Rutgeerts $P$, et al. Adalimumab for maintenance treatment of Crohn's disease: results of the CLASSIC II trial. Gut. 2007;56:1232-9.

21. Sands BE, Anderson FH, Bernstein CN, et al. Infliximab maintenance therapy for fistulizing Crohn's disease. N Engl J Med. 2004;350:876-85.

22. Sandborn WJ, Feagan BG, Stoinov S, et al. Certolizumab pegol for the treatment of Crohn's disease. N Engl J Med. 2007;357:228-38.

23. Schreiber $\mathrm{S}$, Rutgeerts $\mathrm{P}$, Fedorak RN, et al. A randomized, placebo-controlled trial of certolizumab pegol (CDP870) for treatment of Crohn's disease. Gastroenterology. 2005;129:807-18.

24. Schreiber S, Khaliq-Kareemi M, Lawrance IC, et al. Maintenance therapy with certolizumab pegol for Crohn's disease. N Engl J Med. 2007;357:239-50.

25. Sandborn W, Rutgeerts $\mathrm{P}$, Reinisch W, et al. SONIC: a randomized, double-blind, controlled trial comparing Infliximab and Infliximab plus Azathioprine to Azathioprine in patients with Crohn's disease naive to immunomodulators and biologic therapy [Abstract]. Inflamm Bowel Dis. 2008;14(Suppl 3):S1.

26. Solberg IC, Lygren I, Jahnsen J. Clinical course during the first 10 years of ulcerative colitis: results from a population-based inception cohort (IBSEN Study). Scand. J. Gastroenterol. 2009;44:431-440.

27. Issa I. Biologic agents for inflammatory bowel disease: The current, the future and the controversy. BOOK: Inflammation Chronic Diseases and Cancer - Cell and Molecular Biology, Immunology and Clinical Bases. Publisher InTech, March, 2012 ISBN 978953-51-0102-4. 2012;417-430

28. Rutgeerts $P$, Sandborn WJ, Feagan $B G$, et al. Infliximab for induction and maintenance therapy for ulcerative colitis. N Engl J Med. 2005;353:2462-76.

29. Jarnerot G, Hertervig E, Friis-Liby I, et al. Infliximab as rescue therapy in severe to moderately severe ulcerative colitis: a randomized, placebo-controlled study. Gastroenterology. 2005;128:1805-11.

30. Lees CW, Heys D, Ho GT, et al. A retrospective analysis of the efficacy and safety of infliximab as rescue therapy in acute severe ulcerative colitis. Aliment Pharmacol Ther. 2007;26:411-9.

31. Colombel JF, Loftus E, Tremaine W, et al. The safety profile of Infliximab in patients with Crohn's disease: the Mayo Clinic experience in 500 patients. Gastroenterology. 2004;126:19-31.

32. Ljung $T$, Karlen $P$, Schmidt $D$, et al. Infliximab in inflammatory bowel disease: clinical outcome in a population based cohort from Stockholm County. Gut. 2004;53:849-53.

33. Fidder $\mathrm{HH}$, Schnitzler $F$, Ferrante $M$, et al. Long-Term safety of infliximab for the treatment of inflammatory bowel disease: a single centre cohort study. Gut. 2009;58:501-8. 
34. Lees C, Ali A, Thompson A, et al. The safety profile of anti-tumour necrosis factor therapy in inflammatory bowel disease in clinical practice: analysis of 620 patientyears follow-up. Aliment Pharmacol Ther. 2009;29:286-97.

35. Fidder $\mathrm{HH}$, Schnitzler $F$, Ferrante $\mathrm{M}$, et al. Long-Term safety of infliximab for the treatment of inflammatory bowel disease: a single centre cohort study. Gut. 2009;58:501-8.

36. Toruner M, Loftus EV, Harmsen WS, et al. Risk factors for opportunistic infections in patients with inflammatory bowel disease. Gastroenterology. 2008;134(4):929-36.

37. Death toll from listeria outbreaks rises to $29 ; 2012$. Ref Type: internet communication.

38. Structure and initial data and survey for the risk assessment of the public health impact of food-borne Listeria monocytogenes. Food and Drug Association Center for Food Safety and Applied Nutrition; 1999.

39. Dixon WG, Watson K, Lunt M, Hyrich KL, Silman AJ, Symmons DP. Rates of serious infection, including site-specific and bacterial intracellular infection, in rheumatoid arthritis patients receiving anti-tumor necrosis factor therapy: results from the British Society for Rheumatology Biologics Register. Arthritis Rheum Aug. 2006;54(8):236876.

40. Kato K, Nakane A, Minagawa T, et al. Human tumor necrosis factor increases the resistance to listeria infection in mice. Med Microbiol Immunol. 1989;178:337-46.

41. Havell EA. Evidence that tumor necrosis factor has an important role in antibacterial resistance. J Immunol. 1989;143:2894-9.

42. Nakane A, Minagawa $T$, Kohanawa $M$, et al. Interactions between endogenous gamma interferon and tumor necrosis factor in host resistance against primary and secondary Listeria monocytogenes infections. Infect Immun. 1989;57:3331-7.

43. Morelli J, Wilson FA. Does administration of infliximab increase susceptibility to listeriosis? Am J Gastroenterol. 2000;95:841-2

44. Abreu C, Magio F, Vilas-Boas F, et al. Listeria infection in patients on anti-TNF treatment: Report of two cases and review of the literature. J Crohn's Colitis. 2013;7:175-182

45. Becker JM, and Stucchi A. Treatment of Choice for Acute Severe Steroid-Refractory Ulcerative Colitis Is Colectomy, Inflamm Bowel Dis. 2009;15.

46. Fazio VW, Ziv Y, Church JM, et al. Ileal pouch-anal anastomoses complications and function in 1005 patients. Ann Surg. 1995;222:120-127.

47. Fazio VW, O'Riordain MG, Lavery IC, et al. Long-term functional outcome and quality of life after stapled restorative proctocolectomy. Ann Surg. 1999;230:575-584.

48. Carmon E, Keidar A, Ravid A, et al. The correlation between quality of life and functional outcome in ulcerative colitis patients after proctocolectomy ileal pouch anal anastomosis. Colorectal Dis. 2003;5:228-232.

49. Fazio VW, Ziv Y, Church JM, et al. Ileal pouch-anal anastomoses complications and function in 1005 patients. Ann Surg. 1995;222:120-127.

50. Meagher AP, Farouk R, Dozois RR, et al. J ileal pouch-anal anastomosis for chronic ulcerative colitis: complications and long-term outcome in 1310 patients. Br J Surg. 1998;85:800-803.

51. Mowschenson PM, Critchlow JF, Peppercorn MA. Ileoanal pouch operation: long-term outcome with or without diverting ileostomy. Arch Surg. 2000;135:463-465; Discussion 465-466.

52. Young CJ, Solomon MJ, Eyers AA, et al. Evolution of the pelvic pouch procedure at one institution: the first 100 cases. Aust N Z J Surg. 1999;69:438-442.

53. Keighley MR, Grobler S, Bain I. An audit of restorative proctocolectomy. Gut. 1993;34:680-684. 
54. Marcello PW, Roberts PL, Schoetz DJ Jr, et al. Long-term results of the ileoanal pouch procedure. Arch Surg. 1993;128:500-503; Discussion 503-504.

55. Vendrell R, Inesta M, Mera R, et al. Ileal pouch-anal anastomosis for ulcerative colitis: the University of Puerto Rico experience. P R Health Sci J. 2001;20:221-224.

56. Cohen Z, McLeod RS, Stephen W, et al. Continuing evolution of the pelvic pouch procedure. Ann Surg. 1992;216:506-511.

57. Miller JS, Ferguson CM, Amerson JR, et al. lleal pouch-anal anastomosis. The Emory University experience. Am Surg. 1991;57:89-95.

58. Pemberton JH, Kelly KA, Beart RW Jr, et al. lleal pouch-anal anastomosis for chronic ulcerative colitis. Long-term results. Ann Surg. 1987;206:504-513.

59. Meagher AP, Farouk R, Dozois RR, et al. J ileal pouch-anal anastomosis for chronic ulcerative colitis: complications and long-term outcome in 1310 patients. $\mathrm{Br} \mathrm{J}$ Surg. 1998;85:800-803.

60. Young CJ, Solomon MJ, Eyers AA, et al. Evolution of the pelvic pouch procedure at one institution: the first 100 cases. Aust N Z JSurg. 1999;69:438-442.

61. Oussalah A, Evesque L. A Multicenter Experience With Infliximab for Ulcerative Colitis: Outcomes and Predictors of Response, Optimization, Colectomy, and Hospitalization , Am J Gastroenterol. 2010;105:2617-2625.

62. Mor IJ, Vogel JD, Moreira Ada L, et al. Infliximab in ulcerative colitis is associated with an increased risk of postoperative complications after restorative proctocolectomy. Dis Colon Rectum. 2008;51:1202-1207

(C) 2013 Issa and Eid; This is an Open Access article distributed under the terms of the Creative Commons Attribution License (http://creativecommons.org/licenses/by/3.0), which permits unrestricted use, distribution, and reproduction in any medium, provided the original work is properly cited.

Peer-review history:

The peer review history for this paper can be accessed here: http://www.sciencedomain.org/review-history.php?iid=205\&id=12\&aid=1570 